\title{
Study on the Industrialization of Ecological Agriculture in China and the Construction of Its Development Model
}

\author{
LIU Yingyuan ${ }^{1,2, ~ a, ~ F e n g ~ Z h o n g c h a o ~}{ }^{1, b}$ \\ ${ }^{1}$ College of Economics and Management, Huazhong Agricultural University, Wuhan, 430070, China \\ ${ }^{2}$ School of Economics and Management, Hubei University of Technology, Wuhan, 430068, China \\ aemail:2500207860@qq.com, bemail:fengzhch@163.com
}

Key words: Eco-agricultural Industrialization; Problems; Development Model

\begin{abstract}
Industrialization of ecological agriculture is an inevitable choice for the development of modern agriculture. It is a realistic requirement for the sustainable development of agriculture in China and also one of the hot topics in the academic community. Based on a deep analysis of the connotation and characteristics of eco-agricultural industrialization, the article explores the issues faced by the industrialization of eco-agriculture in China, and finally builds a pluralistic-integrative eco-agricultural industrialization model based on domestic and foreign eco-agricultural industrialization models and major types. It also has clarified the development principles that China's agriculture should follow in its transformation towards ecology and industrialization. This is of great significance for the development of industrialization of ecological agriculture in China.
\end{abstract}

\section{Introduction}

Industrialization of eco-agriculture follows the principle of unification of rural economic development and the use of resources and environmental protection of agricultural ecology. Within the carrying scope of the ecosystem, the local advantages of location, ecological resources and comparative advantages of agricultural products will be utilized to achieve agricultural production and ecology. Under the conditions of a virtuous circle, modern agricultural industries that are safer, greener, better-quality, economical, and environmentally efficient have been developed. Through the regional construction, professional production, systematic processing, integrated management, enterprise management and socialized services, the leading enterprises, markets, and farmers are closely linked, gradually forming an interest consortium of "risk sharing, benefit sharing", which promotes a virtuous circle mechanism for the rural economy to enter self-regulation and self-development.

\section{Characteristics of ecological agricultural industrialization}

\section{A. Specialization in production}

The basic requirement of agriculture for industrialization of agriculture is to have high labor productivity and high capital utilization rate. The most basic basis for raising these elements is the need for specialized production, especially in the research and production of agricultural products. The basic form of production today is small and scattered. Therefore, under the specialization requirements, we must organize the unified production under the guidance of regional arrangements. The land policy in this process is without change. The only change is the expansion in the external scale of the peasant households.

\section{B. Layout regionalization}

The industrialization of agriculture should first be regional. In a given area, the production and processing of agricultural and sideline products should be centrally linked, so that it can exert its regional advantages to establish a targeted production base and prevent production instability due to blind industrialization. 


\section{Business integration}

Business integration is essentially the integration of production and marketing. Through organic integration, the whole production process can be unified, with emphasis on "integration". In this industrial chain, the main body of each link must share the overall awareness of risk sharing.

\section{Service socialization}

In traditional agricultural operations, the service system is relatively backward with a heavier government atmosphere. Therefore, it is necessary to establish a socialized service system in the industrialization of agriculture, which is to make the information, capital, logistics and management of the entire production process can all obtain professional services, so that all production entities can actively participate in production and maintain their connections.

\section{E. Management enterprization}

Leading enterprises is an indispensable force in the industrialization of agriculture. Therefore, it is required that leading enterprises should have standardized operations. At the same time, the production base needs strong corporate management awareness and a scientific management model in order to cooperate with leading enterprises to highlight the leading enterprises in the development of large-scale agriculture. .

\section{Problems of industrialization of ecological agriculture in China}

\section{A. The eco-awareness of agricultural producers is relatively weak}

Ecological civilization reflects the direction of social progress, but it still takes a long time to actively combine the green "ecology" with the yellow "agriculture" in people's minds. On the one hand, the power of habits is unparalleled. Many years of farming habits have made people reluctant to reflect on the many shortcomings of traditional agriculture. On the other hand, it is also a more important aspect. Though the use of chemical fertilizers, pesticides and plastic film in traditional agricultural production is irrational, the consumption of agricultural resources is huge and the pollution is serious, rural land as a collective property right makes farmers pay more attention to the immediate interests, so that it is easy to overlook the long-term damage caused by unreasonable operations.

\section{B. The agricultural industry structure is unreasonable}

The first is that the proportion of grain production is too large, which inevitably accompanies the increase in the consumption of fertilizers, pesticides, and other agricultural resources, directly restricting the transition from traditional agriculture to ecological agriculture. Secondly, food production is a kind of necessary production, which makes agricultural producers bear bigger pressure to abandon traditional agricultural production to transform into modern ecological agricultural production. Thirdly, the proportion of grain production is too large, which inevitably means that the proportion of forestry, animal husbandry, fishery and other sideline industries is relatively small, especially the proportion of forestry which is very limited. Forestry is a typical part of ecological agriculture. The low proportion of forestry has also increased the difficulty of developing ecological agriculture.

\section{The basic condition for agricultural production is fragile}

In most regions of China, the capacity of farmland water conservancy infrastructure and the ability to withstand floods and droughts are still weak. A considerable number of mountain rush terraces, sorghum fields, and sloping farmland still "rely on the God" and lack basic irrigation and drainage conditions. In addition, some channels, rivers, dams and ponds have been in disrepair for many years and their functions have deteriorated. What is even more serious is that some agricultural natural ecosystems have been vandalized and the automatic adjustment function has weakened. The fragile basic conditions for agricultural production make agricultural producers 
more dependent on small-scale and inefficient production methods in the development of ecological agriculture.

\section{The agricultural financial system is deficient}

A sustained and effective financial system is essential to the development and operation of any economic model. At present, the loans for Chinese eco-agriculture enterprises mainly consist of rural cooperative institutions and rural commercial banks, supplemented by state-owned banks and joint-stock banks. It is difficult for rural cooperative agencies and rural commercial banks to provide a fully-fledged and diversified financial support system. In particular, with the tightening of financial policies in the past two years, state-owned banks and joint-stock banks have experienced problems in loan procedures, high barriers to entry, and the financial system in rural areas is even worse.

\section{E. The guiding role of the government needs to be improved}

The industrialization of ecological agriculture, as a new thing, is inseparable from the guidance and support of government departments. On the one hand, the government's policies to support the development of ecological agriculture must be continuously improved. For example, the government needs to improve the standardization, testing and market supervision capabilities of ecological agricultural products. At present, the so-called ecological agricultural products in the market are mixed and the government inspection, quarantine, and testing are not comprehensive enough. The quality of ecological agricultural products has not yet been fully guaranteed and their responsibilities are difficult to be traced back. From the perspective of improving policies, the government needs to establish an authentication mechanism for ecological agricultural products, and strictly implement unified standard certification based on universal green detection indicators in world trade. On the other hand, the government must increase the implementation of the issued policies. Since the policy has not been put in place, the related subjects still encounter many policy and implementation barriers in the process of developing ecological agriculture industrialization.

\section{Development of eco-agricultural models at home and abroad}

The research on ecological agriculture in developed countries has been going on for decades. In 1970, American soil scientist W. Albreche proposed the concept of "ecological agriculture" for the first time, and then the overseas research on ecological agriculture models and technologies also followed. Some typical studies of foreign eco-agriculture models are American low-input and sustainable agriculture research model, German internal farm material circulation and organic farming model, Japan's natural agriculture and three-dimensional agricultural model, and the ecological agriculture model organized by the Indian Ecological Farmers Association. Judging from the research content, the construction of foreign eco-agricultural models focuses on crop rotation, expanding the cultivation of legume crops, applying organic fertilizers, biological control, and reducing or reducing the use of chemical substances such as chemical fertilizers and pesticides. These models have played a positive role in improving the ecological environment and cultivating soil fertility, but the thought of agricultural substitution has also been emerged in some extreme ways to curb chemical inputs.

\section{Pluralistic-integrative eco-agricultural industrialization model and its development principles}

Aiming at a series of problems in China's ecological agriculture, we must implement the industrialization of ecological agriculture and take the most effective model of industrialization of ecological agriculture as the main direction of agricultural development in China. Therefore, the eco-agricultural industrialization management model was elaborated, and the main development models of eco-agricultural industrialization at home and abroad were introduced and analyzed, in order to provide a reference and promotion role for the industrialization transformation of 
eco-agriculture in China.

\section{A. Construction of the pluralistic-integrative eco-agricultural industrialization model}

Based on the analysis of the connotation, main types and development models of industrialization of eco-agriculture, this study has constructed a pluralistic-integrative eco-agricultural industrialization model and industrialization process, as shown in Figure 1.

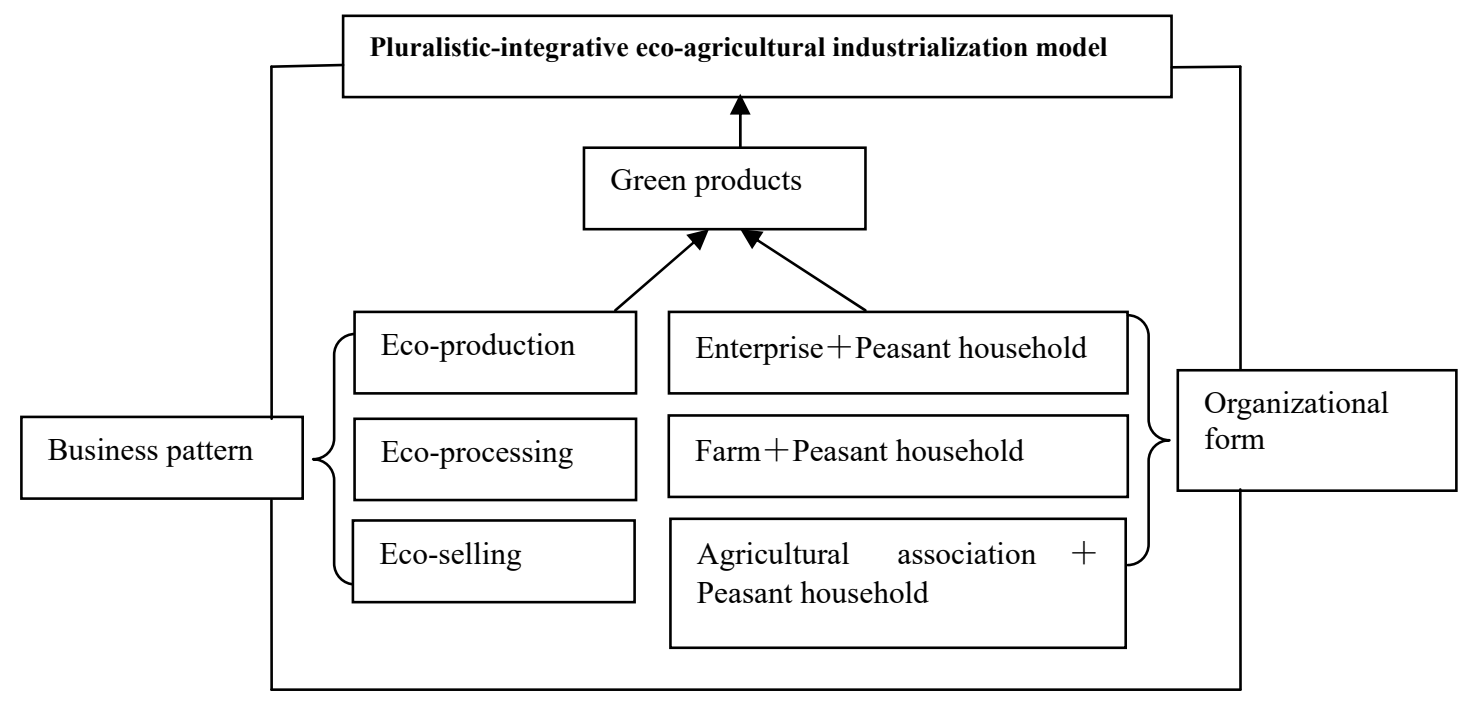

Figure 1 the pluralistic-integrative eco-agricultural industrialization model

\section{B. The principle of development of pluralistic-integrative eco-agricultural industrialization model}

a. Follow the basic principles of eco-agricultural construction

Adhere to the coordination of the relationship between man and nature as the development goal, and achieve comprehensive multi-objective decision-making. Not only pursue agricultural production and economic results, but also take into account the social and ecological environmental benefits. Follow the fundamental principles of "integration, coordination, recycling, and regeneration" of ecological project, pay attention to the coordination of various subsystems within the large-scale system and between various factors within the subsystems, maintain a reasonable ecological and economic structure of the large-scale system, and ensure the recycling and utilization of natural resources. While promoting traditional agricultural technology, we must pay attention to absorbing modern science and technology. According to the multi-objective requirements of sustainable development of agriculture, systematic engineering methods should be used to assemble various modern agricultural individual technologies in accordance with local conditions and to exert their overall functions. Emphasize the structural optimization of the agriculture, forestry, animal husbandry and fishery system, and form an integrated agricultural system with ecological and economical optimization and mutual promotion; pay attention to giving full play to the special functions of various professional and industrial sectors, and emphasize the importance of different professions and different industrial sectors at different levels. Collaborate fully to establish a coordinated and integrated management system.

b. Follow the principle of geographical differentiation and ecological suitability

In order to fully exploit the local ecological resources and form regional characteristic industries, the overall planning and design of the ecological agriculture industry should be based on comprehensive investigation and analysis of resource potentials, ecological disadvantages and advantages, and market conditions. The design must consider the optimal function and effect of the system as a whole; the hierarchical use of substances and energy; the diversity, stability, and orderliness of the ecological agricultural system. Increase the anti-jamming capability of the system; increase the input of organic energy and maintain the dynamic balance of the nutrient circulation of 
the system.

c. Improve the scientific and technological content of industrialization of ecological agriculture.

Further strengthen the content of agricultural science and technology, pay attention to the construction of township agricultural technical stations, and improve the ecological agricultural science and technology promotion network. Introduce and promote key and practical technologies, especially deep-processing technologies for various types of agricultural products and biological preservation and storage technologies for fruits, vegetables and edible fungi, and timely solve technical problems in the industrialization of ecological agriculture. The scientific and technological innovation of ecological agriculture should be carried out, and through the combination of scientific and technical personnel of universities, research institutes, and extension departments with farmers, there has been continuous innovation in production practices. Strengthen the training of scientific and technological culture for agricultural workers and create a group of rural science and technology talents.

d. Pay attention to the comparative advantages of the development location.

The ultimate manifestation of regional advantages is the market competitiveness of agricultural products. Since the comparative advantage will change with changes in its own conditions and external environmental conditions, it is required that the industrial structure in various places be continuously adjusted, optimized, and upgraded. In addition to the advantages of natural resources, regional comparative advantages include transportation, location conditions, marketing conditions, production technology and management level, and products' production scale and specialization.

e. Strengthen the market system construction

The industrialization of eco-agriculture is market-oriented and guides production, processing and sales according to market demand information and price signals. To a certain extent, the industrialization of ecological agriculture is the marketization of ecological agriculture. Therefore, it is particularly important to cultivate and regulate the green market. In the production areas or distribution centers of key ecological agricultural products, a batch of large and medium-sized professional wholesale markets for ecological agricultural products will be established in a planned and systematic manner, and a number of green food distribution centers will be selectively established in large and medium-sized cities in an effort to form a broader range of sales network of ecological agricultural products and green food. And a mechanism that is in line with the world's green agricultural products market should be built, and through the expansion of the scope of the green product market, it will stimulate the development and growth of ecological agriculture industrialization.

\section{Conclusion}

The rapid development of agriculture has severely tested the resources and ecological environment, and how to make a sustainable development has become a problem that needs to be solved. The industrialization of ecological agriculture has become the only choice for cracking. The development model of eco-agricultural industrialization is the organization method of realizing large-scale economic benefits while protecting the sustainable productivity of the eco-environment of agricultural resources, and is a means of industrializing eco-agriculture. Based on the analysis of the current situation and problems faced by the industrialization of ecological agriculture in China, according to the existing ecological agricultural development model, a pluralistic-integrative ecological agriculture is proposed, combined with the optimization trend of advanced ecological agricultural development models at home and abroad. This model can guide the development and construction of ecological agriculture in China, and at the same time provide a realistic basis for the development of eco-agricultural industrialization in central mountainous regions.

\section{References}

[1] Eeo-industrial development:A strategy for building sustainable community. Schlarb M. Reviews of Economic Development Literature and Practice . 2001 
[2] Rural development and the regional state: Denying multifunctional agriculture in the UK[J] . Terry Marsden,Roberta Sonnino. Journal of Rural Studies . 2008 (4)

[3] The Role of the Firm and Owner Characteristics on the Performance of Agritourism Farms[J] . CarlaBarbieri,Patience M.Mshenga. Sociologia Ruralis . 2008 (2)

[4] Rural governance, community empowerment and the new institutionalism: A case study of the Isle of Wight[J] . David Clark,Rebekah Southern,Julian Beer. Journal of Rural Studies . 2006 (2)

[5] Matching demand and supply in the agricultural knowledge infrastructure: Experiences with innovation intermediaries [J] . Laurens Klerkx, Cees Leeuwis. Food Policy . 2007 (3) 